\title{
The Enclosure of the Zuider Zee
}

\section{By Dr. Brysson Cunningham}

$\mathrm{M}$ AY 28 last will always be a notable date in the annals of the Netherlands. On that day, in the presence of distinguished government officials, the crucial deposit of clay was made which finally and entirely cut off the waters of the Zuider Zee from any intermingling with the outer sea. The means of severance, it is true, is but a narrow earthen embankment, stretching like a taut cord country and of ten per cent in the area of arable land. Relatively, it is as if Holland were enlarged by the addition of a province roughly equivalent in size to Kent or Essex or Sussex.

In NATURE of Sept. 21, 1929, following a visit to the site of the works, I gave an outline of the scope and probable effects of this tremendous projeet, which has, for several centuries past, occupied

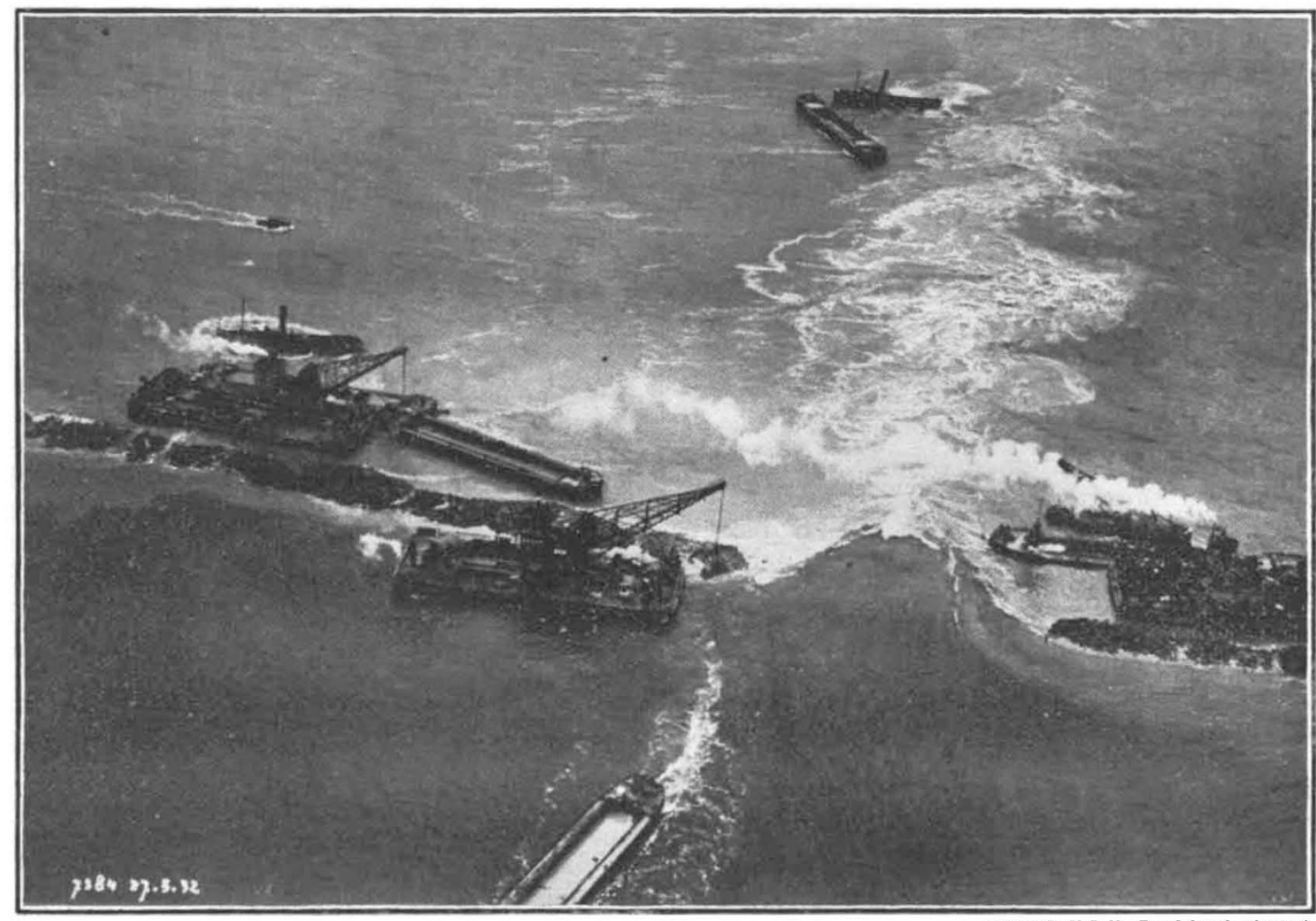

FIa. 1. - The concluding stage in the enclosure of the Zuider Zcc, showing plant in opcrution.

or strip of ribbon, for a length of $18 \frac{1}{2}$ miles, from the eastern extremity of the former island of Wieringen to the Friesian coast, but it suffices to create an impassable barrier, intersected only by three locks for purposes of navigation and by two groups of sluices for surplus water discharge, and it marks the commencement of a distinctly new regimen for the impounded area.

Hitherto, this vast expanse of nearly a million acres of water has been an arm of the sea; at present, it is an inland lake, the greater part of which is destined to be pumped dry and converted into agricultural holdings, while the residue will constitute a reservoir for fresh water, instead of salt water, to be utilised, apart from navigation, as a source of supply for irrigation and farming. In the ultimate result, the transformation will mean an increase of seven per cent in the area of the whole the minds of the Dutch people and exercised the ingenuity of their engineers. Living, as they do, within a territory of restricted extent, much of it lying below sea-level and subject to tidal inundation, they have been compelled, at much trouble and expense, to win from the sea such tracts as were possible in order to find scope for the natural expansion of the population and their industrial activities. According to statistics published in 1924, there had then been an increment of about 250,000 acres, gained since the year 1846. Including the exploitation of land previously considered as waste, the total increase in arable land during the last century has been rather more than a million acres, equivalent to a rate of 10,000 acres a year, but against this must be set off the loss due to building and engineering operations, latterly at the rate of about 6000 acres a year. This leaves a

No. 3272 , VoL. 130$]$ 
net annual gain of 4000 acres per annum; but the population is growing fast, and there is at the present time a distinct shortage of arable land.

The acquisition of so large an area as that covered by the Zuider Zee naturally involved a multitude of complex problems, so that it was only after protracted consideration and many financial and legislative delays, inseparable from an undertaking of such magnitude, that the work was actually commenced in 1920 . It has therefore been in progress over a period of twelve years. In accordance with the plan prepared by the late Dr. C. Lely, it involved the construction of a main dyke, or embankment, which, starting from the little village of Van Ewijcksluis on the eastern coast of the province of North Holland, extends across a deep strait of $1 \frac{1}{2}$ miles to the western side of the island of Wieringen, to be resumed at Den Oever at the eastern extremity of the same island, and thence, apart from a slight curvature at the eastern end, to stretch in a straight line eastwards as far as the village of Zurig on the coast of the province of Friesland. South of the main dyke, or enclosing dam, a series of four separate areas or 'polders' with an aggregate content of about 550,000 acres, is to be reclaimed by pumping out the water into a central lake of about 270,000 acres, provisionally designated the Yssel Lake and designed to receive the discharge of the rivers Yssel, Zwartewater, and Vecht from the mainland. The first of these polders has, in fact, already been reclaimed and the progress made thereon will be referred to later.

For the moment, attention is directed to the concluding stages of the work in connexion with the main dyke, which, with the four polders, is shown in the map accompanying my article in NATURE for Sept. 21, 1929.

At the time of writing the above article, the island of Wieringen had already been joined up to the mainland and a substantial roadway formed a.cross the Amstel Diep. The work was proceeding in the main dyke from both extremities, namely, eastwards from Den Oever and westwards from the Friesian coast across the shallows of Makkummerwaard to the site of the navigation locks at Kornwerderzand, a distance of $2 \frac{1}{2}$ miles. Approximately half-way between the Kornwerderzand and Den Oever, lies another shoal area, called the Breezand. Advantage was taken of its existence to commence, in 1929 , a detached mid-sea section, which has been extended eastwards and westwards to link up with the coastal sections. The intervening spaces were crossed by two deep 'guts' or channels, the Vlieter on the west and the Middelgronden on the east, in which the depth of water increased to as much as 10 metres. These channels were first treated with shallow deposits of material to form 'sill dams', reducing the depth of water over them to more convenient limits. The material consisted of a layer of boulder clay protected by a covering of 'mattresses' of brushwood, weighted down in position by means of heavy stone fragments and secured by stakes driven into the ground. The mattresses were arranged to extend appreciably beyond the limits of the main dyke, in order to ensure protection from scour. These sills were completed in 1930.

When, a year later, preparations were made to proceed with the formation of the dam itself on these sills, it was found that the brushwood, while maintaining its position, had suffered a good deal

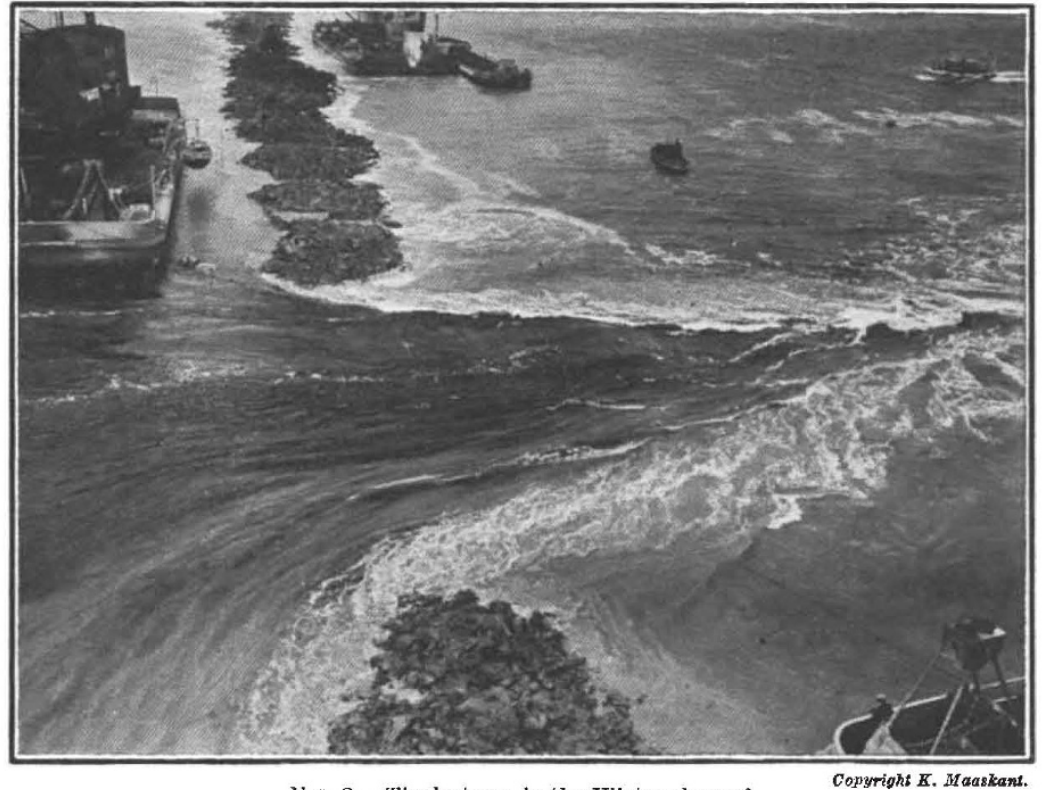

FIG, 2.--The last gap in the Vlieter channel.

from the attacks of marine borers, and that considerable corrosion of the galvanised binding wire had taken place. The sill on the Middelgronden had deteriorated to a greater extent than that on the Vlieter, and, accordingly, first attention was given to the execution of the main structure across the former. It was completed in November 1931. The work carried out during the first half of the current year has been the final closing length across the Vlieter.

The method of forming the main dyke consisted in first depositing a substantial body of boulder clay to form a nucleus and a frontal barrier. Behind this was discharged a mass of sand (dredged within the limits of the Zuider Zee and transported to the site), which was covered in turn by a layer of clay, or boulder clay, the latter being a specially tough variety of glacial origin, containing boulders, found in the floor of the Zuider Zee in various places, as well as on the island of Wieringen and on the south coast of the province of Friesland. It has proved eminently suitable for resisting the scouring action of currents, and its qualities in this respect were 
fully tested during the period of concentrated flow while the tidal water was passing in and out of the gradually contracting gap, as can be well seen from the photographs in Figs. 1 and 2 taken the day before the final closure was made. I had an opportunity myself of witnessing the concluding stage of the construction of the dam flanking the new northwest polder, and was much impressed by the resistive capacity of the material. As a final covering, the exposed surface of the embankment is protected below the water-line by mattresses of brushwood, weighted with rip-rap, and above the water-line by a stone facing of basalt or limestone, brought from Germany.

A point of interest that requires mention is the effect of the constructional operations on the tidal conditions. It is stated that up to the end of 1929

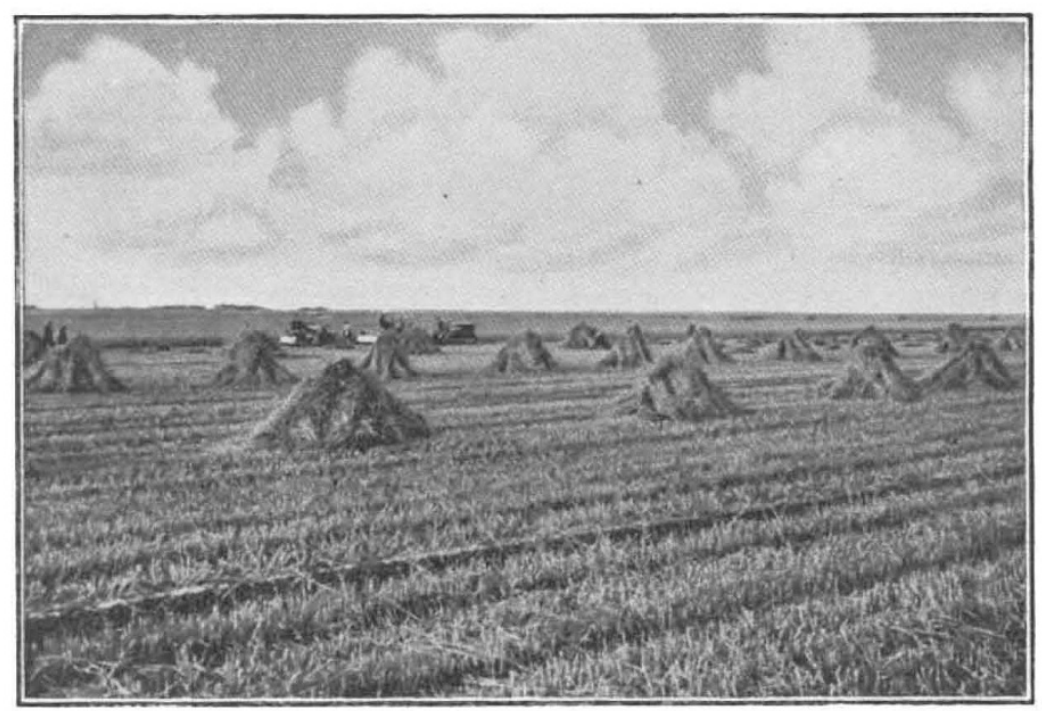

FIG. 3.-Harvesting the first crop of rye on the Wieringermeer.

with the exception of a period in 1924 due to the closing of the Amstel Diep between the island of Wieringen and the mainland), there had been scarcely any changes in the tidal movement. Afterwards, as a result of the formation of the sills in the channels of Middelgronden and Vlieter, the velocity of flow across the line of the dam increased to a marked degree, reaching $3-3 \frac{1}{4} \mathrm{ft}$. per second, while, at the same time, certain changes were manifesting themselves in the rise of the tide in the outer area, very perceptibly in the Texel Strait and less noticeably in the Vlie Strait. These changes will require further observation before they can be definitely evaluated, but they appear to be of the order of 6-12 inches, generally, in the Wadden Zee.

Concurrently with the construction of the main dyke, operations have been in hand for developing the new north-west polder (Wieringermeer) of 50,000 acres, which was reclaimed by the formation of an auxiliary dyke in advance of the main project. It was pumped out in 1930 , the quantity of water discharged within a period of six months being more than 132,000 million gallons. The land, of course, had been covered with sea water for cen-
Copyright $\boldsymbol{K}$. Masskant.

turies and the soil was heavily charged with salt. The mean salinity ranged from $\frac{1}{2}$ to 2 per cent, the variation being due to the proximity, in certain parts, of fresh-water outlets from land drainage systems. A surface soil chart is in course of preparation, for which purpose borings are being taken on every plot of 5 hectares to a depth of $1 \frac{1}{2}$ metres. The result of the investigation in regard to the first polder-section shows that the surface layer is of unequal thickness and consists mainly of sand, under which clay is often found, and, further, of a small percentage of clay and sandy clay with a small amount of peat. There appears, however, to be considerable dissimilarity of structure in different areas.

One of the earliest and most important problems to be solved before cultivation could be attempted was that of internal drainage. The first intention of providing a network of shallow trenches was abandoned, as it failed to drain the sub-soil sufficiently, or to remove the salt. Coveredin drains would have been preferred, but the cost was high, and, finally, recourse was had to a system of open trenches on a large scale. They have a depth of $60 \mathrm{~cm}$. and are arranged at distances apart of 11 metres in clay areas and of 15 metres in sandy areas. In the spring of 1931, the sampling of soil showed that about 400 hectares of sandy ground in polder-section No. 1 was suitable for cultivation (Fig. 3), while the ground with a higher clay composition still retained an excess of salt. In the autumn, further tests were made, as a result of which, 1050 hectares were declared suitable for planting with cabbage, or sowing with winter barley and wheat, while 900 hectares were treated with a mixture of grass and clover seed to develop permanent pasturage.

The remarkable experiment of bringing the Zuider Zee into a state of agricultural productivity will be watched with the greatest interest, as its economic value to the inhabitants of the Netherlands is a matter of no little importance. In 1924, the outlay on the main dyke and the reclamation of the polders until the latter attain their full cultivable state was estimated at about thirty million pounds, to which interest over the unproductive period would add some fifteen millions, making a total of forty-five millions. The profits to be derived had, of course, to be evaluated on a more or less speculative basis, but they were put at a figure of fifty-two millions. In 1928, it was reported that actual costs to date had exceeded the estimates by some five millions, due to the rise in prices of public works, particularly dredging, and certain constructional difficulties, which could not have been foreseen. Since then, there have been

No. 3272, VoL. 130] 
some reduction in prices, and if the favourable conditions continue, it is hoped to complete the undertaking without further excess and even with some reduction of the debit.

Everyone will hope that this enterprise of high courage and endeavour will be crowned with the success it deserves. Very great credit is due to its promoters and to the engineering staffs who have faced and overcome all the difficulties which have arisen from time to time. I am indebted to Dr. Ir. J. A. Ringers, director-general of the Rijks- waterstaat, for the photographs reproduced and the greater part of the information on which this article is based. For several years he was in charge of the operations, as director of the association of contracting companies expressly formed for the execution of the project, known as the Maatschappij tot Uitvoering van Zuiderzee-werken. On the Government side, mention should be made of the Zuiderzee Board, with Dr. H. Colijn at its head, and the office of the Zuiderzee works, to which Mr. V. J. P. de Blocq van Kuffeler is director-general.

\section{Basic English *}

BOUT three centuries have now elapsed since A three master minds-Descartes, Pascal, and Leibniz-espoused the cause of a lingua franca, and ingenious attempts are still being made to devise or construct a synthetic language for international use. The case for the adoption of an international auxiliary language (I.A.L.) is stronger now than it has ever been, but results have so far been disappointing. Though several of the projects that have been put forward might, with more or less modification, have proved satisfactory, practically none, with the exceptions of Volapük and Esperanto, has gone far beyond the threshold of the academy or the study. As Prof. Donnan has said, so far as numbers are concerned, Esperanto is the greatest and most successful linguistic experiment that the world has seen. The causes of failure are mainly psychological. Mankind is not ruled by reason, and the idea or ideal of an I.A.L. does not appeal to man's pleasurable emotions or to his primary instincts, except probably to that of pugnacity, for enthusiasts in this field have shown almost as little brotherly love to competitors as did rival religionists in days now happily past. Another obstacle has been the widespread fallacy that anything artificial is ipso facto inferior to its natural counterpart. However, the cause endures, and the latest apostle, Mr. C. K. Ogden, comes forward with a simplified form of English, called Basic, to compete, and peradventure to conquer, in the field of international linguistics.

The main features of Basic, which derives its name from the initial letters of the words, British, American, Scientific, International, Commercial, are : a very restricted vocabulary of nouns $(600)$; the use of only sixteen or seventeen verbs, including come, get, give, go, keep, let, make, put, seem, and a few others ; the use of 150 adjectives and a number of prepositions, adverbs, pronouns, and conjunctions, but apparently no interjections. The grand total is 850 words, but further nouns can be created by adding the suffixes -er, -ed, and

\footnotetext{
* "Basic English Applied (Science)," By C. K. Ogden. With specimen Translations in Chemistry, Physics, and Biology, by $R$. Michaelis. Pp. 88. "The Basic Traveller: and other Examples of Basic Fnglish." By L. W. Lockhart. Pp. 119. "The Basic Vocabulary: a tion." By C. K. Ogden. Pp. 96. "The Basic Dictionary: being the 7500 must Useful Words with their Hquivalents in Basic English; for the Use of 'Translators, Teachers, and Students," By C. K. Ogden. Pp. $x x+106$. "Debabelisation: with a Survey of Contemporary Opinion on the Problem of a Universal Language., Pp. 171. "Basic English: a General Introduction with Rules and Grammar." By C. K. Ogden. Pp. 95. (London: Kegan Paul and Co., Ltd., 1930-1932.) Each vol. 2s. 6d. net.
}

No. 3272 , VoL. 130] -ing to 300 of the primary nouns. Word-order is essentially the same as in good English, although the adverb is banished to the end of the sentence. Pronunciation is to be standardised by means of gramophone records, but spelling is not to be simplified or made phonetic.

Perusal of the Basic textbooks leads to the conclusion that simple conversations could be carried on with the above 850 words and simple derivatives, although in places the phraseology would appear strange, ambiguous, or prolix. Thus, a witch is "a woman with strange powers"; a widow is "a woman not married again" (every divorcée who does not re-marry is thus conveniently made a widow !); and a baby is "a diminutive object". We must not study or use Basic, but "go into" it and "make use of "it. If we are in difficulty, we must not ask but "make a request" for explanation ; we must " make dry " our eyes if we cry ; and "get off the ship" when we come to land. "Friday", we are told, "is the day all the week's payments are made"; and for dinner we are asked," What sort of beef will you have, cooked in the oven or over the fire?" (roast, or boiled, fried, or stewed!). Mercifully, we never " die", we merely " take our last breath " or " go to our end".

This simple but circuitous language would be useful to a foreigner wishing to learn something better than 'pidgin' 'English ; it is easy to acquire and to use, and it would serve him as a good introduction to Fnglish proper; but it seems certain that the 850 words, plus the simple derivatives of the primary nouns, would not suffice for any except very elementary purposes. It is true that provision is made for expanding the primary vocabulary to 1000 words by including in it 150 names of general utility, and further additions, for example, 12 international names, 12 (only) names of sciences, and other proper names are also permitted; but would the foreigner remain content with these? Would he not ask for more, in order to read English newspapers and literature, as well as to converse and correspond with educated Englishmen? English-speaking peoples themselves would not find it easy to talk 'pure' Basic; they would be hard put to it to remember which nouns were in the vocabulary and which were not. For international use, it would be difficult to standardise this language, and the fact that it has a national basis would undoubtedly impede its adoption. 